\title{
Overview of the nutritional status of the Mexican population in the last two decades
}

\author{
Juan A Rivera, PhD, (I) Laura M Irizarry, MS, (I) Teresa González-de Cossío, PhD. (I)
}

$T_{b}^{\text {h }}$

The first national nutrition and diet survey on a probabilistic sample representative of the Mexican population was conducted in 1988. The Mexican National Nutrition Survey 1988 (ENN 88) established a baseline and laid the ground upon which more recent surveys have built upon. Originally developed and analyzed by a team of researchers at the Ministry of Health ${ }^{1}$ the data gathered for the ENN 88 was also evaluated by researchers at the National Institute of Public Health (INSP) who generated several publications about the nutritional status of the population and its determinants. ${ }^{1-7}$ Ten years later, the INSP sought financial support from the Ministry of Health and other organizations to conduct the second national nutrition survey. Care was taken to use a design similar to the one followed for the first survey in order to generate comparable information. Together, the Mexican National Nutrition Surveys of 1988 and 1999 (ENN 88 \& ENN 99) generated a comprehensive picture of the extent, distribution and trends of nutrition issues in the country and associated determining factors over time.

According to the ENN 99, the leading problems resulting from poor nutrition in Mexico were linear growth retardation (stunting), anemia and those resulting from several micronutrient deficiencies. At this time the rise of overweight and obesity was first identified as a public health concern. The results of the ENN 99 were disseminated to the scientific community and presented to government authorities responsible for the formulation of nutrition and health policies and to other key actors in charge of the design and management of nutrition related programs. Given the severity of the implications of the multiple nutrition issues facing the population these results set in motion various public actions, including policies, and programs for preventing malnutrition. Although an emphasis was placed in attending to undernutrition issues, overweight and obesity also became a concern to policy makers and the population at large..$^{8-21}$

The Mexican National Health and Nutrition Survey 2006 (ENSANUT 2006) builds upon the 1988 and 1999 surveys, capturing the evolution of the nutritional status of the Mexican population over an 18 year period. It should be noted that for the first time, representative data at the State level and for all age groups was collected in this survey, what will facilitate the evidence necessary for the development of strategic policies and programs in the future. This paper presents an overview of the nutritional status of the population in the last two decades and discusses the most relevant findings of the ENSANUT 2006. Presented in several articles in this special journal issue and elsewhere, the findings discussed evaluate the determinant factors of both undernutrtion and overnutrition in the context of the double burden of disease over time, and their implications looking ahead.

(I) Instituto Nacional de Salud Pública. Cuernavaca, Morelos, México.

\footnotetext{
Address reprint requests to: Dr. Juan A. Rivera. Instituto Nacional de Salud Pública. Av. Universidad 655, col. Santa María Ahuacatitlán. 62100 Cuernavaca, Morelos, México. E-mail: jrivera@insp.mx
} 


\section{Materials and Methods}

\section{Data sources}

The data sources considered in this article are the nationally representative nutrition surveys conducted in 1988, 1999 and 2006. All three surveys were representative at the national level and by geographical region:* North, Center, Mexico City and South. It should be noted that the 1999 and 2006 surveys were also representative of other geographical units described below. The use of a similar methodology in all three surveys allowed for the comparison of data over time, except noted otherwise.

The ENN 88 was the first national probabilistic nutrition and diet survey conducted in Mexico. Carried out by the Ministry of Health, it collected data from over 13000 households including almost 19000 women aged 12-49 years and more than 7500 children $<5$ years of age. ${ }^{1,3,4}$ With a more comprehensive design and reach, the ENN 99 collected data from close to 18000 households. Data were collected across the country and aggregated by localities with $<2500$ inhabitants (rural) and urban localities ( $\geq 2500$ inhabitants). For some specific analyses, data on localities were further subdivided in those between 2500 and 15000 inhabitants and those with 15000 or more inhabitants, as well as into four general regions (North, Center, South and Mexico City). ${ }^{18,20}$ Age groups were categorized as follows: children $<5 \mathrm{y}$ $(\mathrm{n}=8011)$, children $5-11$ y $(\mathrm{n}=11$ 415) and women $12-49 \mathrm{y}$ $(n=18311) .{ }^{21}$ The 2006 Survey collected data from 48600 households. In addition to being nationally representative and representative of the main four geographical regions, rural and urban areas, the ENSANUT 2006 was also representative at the state level. Subjects were categorized into four age groups: children $<5$ y $(\mathrm{n}=$ 6 937), children 5-11 y ( $\mathrm{n}=15$ 111), adolescents $12-19$ y $(\mathrm{n}=14578)$ and adults $>20 \mathrm{y}$, considering for the first time adults over 49 years of age $(n=33624) .{ }^{22}$

In all three surveys anthropometric, dietary and sociodemographic data were collected. Other key indicators such as hemoglobin concentrations were

\footnotetext{
* The regions included the following States. North: Baja California, Baja California Sur, Coahuila, Chihuahua, Durango, Nuevo León, Sonora y Tamaulipas. Center: Aguascalientes, Colima, Guanajuato, Jalisco, México -excluding the municipalities which are part of the Metropolitan Area of Mexico City-, Michoacán, Morelos, Nayarit, Querétaro, San Luis Potosí, Sinaloa y Zacatecas. Mexico City: Distrito Federal and municipalities which are part of the Metropolitan Area. South: Campeche, Chiapas, Guerrero, Hidalgo, Oaxaca, Puebla, Quintana Roo, Tabasco, Tlaxcala, Veracruz y Yucatán.
}

also assessed. All questionnaires, measurements, and biological samples were collected for the total sample or for sub-samples. Subject recruitment and study procedures were previously approved by the Human Subjects and Ethics Committee of the National Institute of Public Health for the 1999 and 2006 surveys and by the Ministry of Health in the 1988 survey.

Detailed descriptions of the methods followed for data collection have been published elsewhere for the $1988,1,3,4$ the $1999^{18,20}$ and $2006^{22}$ surveys. For the ENSANUT 2006, a thorough description of data collection methods are presented in this issue, specifically for: general dietary data, ${ }^{23}$ anthropometric measurements for the assessment of excess weight in children under five years of age, in children 5-11 and adolescents 12-18 24 and adults, ${ }^{25}$ dietary intake of children, ${ }^{26}$ adolescents ${ }^{27}$ and adults, ${ }^{28}$ hemoglobin determination and definition of anemia in women ${ }^{29}$ and children, ${ }^{30}$ and child malnutrition $^{31}$ in the articles that comprise this special issue, as noted.

A general description of the data collection methods and a list of the variables relevant to this article follow:

Anthropometric measurements, age in months, and sex were used to calculate weight/age, height/age, and weight / height $Z$ scores for of children $<5$ years of age. ${ }^{32}$ The prevalence of undernutrition (stunting, wasting and underweight) was calculated using minus 2 Z-scores of each indicator (length or height for age, weight for length or height and weight for age) as specific cut-off points for age and sex. Prevalence of overweight in children $<5 y$ was defined as weight for length/height above +2 Z-scores. The 2006 growth references set forth by the World Health Organization (WHO) ${ }^{32}$ were used for the first time to assess nutritional status in this publication and in the article by González de Cossio et al. ${ }^{31}$ published in this issue.

Overweight and obesity classifications for children and adolescents are based on Body Mass Index BMI $\left(\mathrm{Kg} / \mathrm{m}^{2}\right)$, using the International Obesity Task Force (IOTF) criteria. ${ }^{33}$ In adults, the BMI was calculated to determine their status based on the cutoff points proposed by the WHO: below 18.5 classified as underweight, 18.524.9 for adequate BMI, 25-29.9 for overweight and 30.0 and over for obesity. ${ }^{34}$ Values outside pre-determined plausible boundaries were excluded. Among preschool children (2 to 4 years) the upper and lower valid values were $10 \mathrm{~kg} / \mathrm{m} 2$ and $38 \mathrm{~kg} / \mathrm{m} 2$; for school-age children $(10 \mathrm{~kg} / \mathrm{m} 2$ and $38 \mathrm{~kg} / \mathrm{m} 2)$, and for adolescents $(10 \mathrm{~kg} /$ $\mathrm{m} 2$ and $58 \mathrm{~kg} / \mathrm{m} 2$ ).

In accordance with the guidelines set forth by the International Nutritional Anemia Consulting Group (IN$\mathrm{ACG})^{35}$ and $\mathrm{WHO}^{36}$ guidelines, anemia was defined as a 
concentration of $\mathrm{Hb}<95 \mathrm{~g} / \mathrm{L}$ for children 6 to 11.9 months of age; $\mathrm{Hb}<110 \mathrm{~g} / \mathrm{L}$ for children 12 to 71 months and $\mathrm{Hb}<$ $120 \mathrm{~g} / \mathrm{L}$ for children 6 to 11 years of age. Hb values lower than $5 \mathrm{~g} / \mathrm{dL}$ or higher than $18.5 \mathrm{~g} / \mathrm{dL}$ were considered spurious and excluded from the analysis. ${ }^{37-40}$ In adult women anemia was defined as a hemoglobin concentration below $12.0 \mathrm{~g} / \mathrm{dL}$ at sea level for non-pregnant women and below $11.0 \mathrm{~g} / \mathrm{dL}$ for pregnant women, according to the WHO recommendations. ${ }^{36}$ In all cases hemoglobin concentrations were adjusted for altitude using Cohen and Hass's equation. ${ }^{41}$ Nutrient adequacies were estimated based on the Estimated Average Requirements for energy (EAR), the Recommended Dietary Allowances for energy (RDA), ${ }^{42}$ and the Dietary Reference Intakes $(\mathrm{DRI})^{43}$ for iron, zinc, vitamin $\mathrm{A}$ and $\mathrm{C}$, and folate, when available. In the 1988 and 1999 surveys a 24-hour dietary recall was used to evaluate dietary patterns. Unlike the ENN 99, in which a 24-hour dietary intake questionnaire was applied, in the ENSANUT 2006 food frequency questionnaires were used to collect dietary information. The decision to use a different methodology for the 2006 analysis was taken based on the underestimation bias associated to 24-hour dietary recalls, particularly as an increased tendency for individuals to eat away from home has been observed, along with the complexity involved in the data collection, processing and management of the 24-hour recall questionnaire in large surveys such as the ENSANUT 2006.

Several of the analyses are presented and discussed in the context of geographic region and/or rural and urban areas (as previously described), age group, and Socioeconomic Status (SES) classification. In the ENN 99 and ENSANUT 2006 Indigenous population was defined according to households in which at least one woman 12-49 years of age (1999) or $>12$ years of age (2006) spoke a Native language. In 1988 a population was classified as indigenous when an indigenous language was spoken in $40 \%$ or more households in a municipality. SES conditions were assessed using information on construction materials used to build the house, sanitary infrastructure, services available (i.e. running water, electricity), and possessions of selected household goods based on a combination of questionnaires and observations. Based on this information an SES indicator was derived from the first component of a Principal Components Analysis ${ }^{44}$ and was divided into tertiles, quintiles or deciles, for different analyses.

Although the three national nutrition surveys followed a similar design and methodology in order to accurately describe changes in the population's nutritional status over the years, at times different dietary tools had to be used. As previously noted, in 1988 and 199924-hour recall questionnaires were used to evaluate consumption patterns; in 2006, food frequency questionnaires were applied. While all three surveys included children $<5$ years and women $12-49$ years, the ENN 99 also included school age children. For the first time, the ENSANUT 2006 also included data and additional information variables for children of all ages, male adolescents and adults, and the elderly population. Indigenous households were defined using different criteria in the three surveys as noted above. Also, measurements collected to assess physical activity patterns differed between the 1999 and 2006 surveys, and were not measured in 1988.

Analyses were performed using STATA (Stata Statistical Software, Version 9.2, and Stata Corporation College Station, TX) and SPSS (SPSS for Windows, Version 15.0, Chicago, IL, SPSS Inc.) taking into consideration the multistage sampling methodology of the study.

\section{Results}

This section summarizes the magnitude, distribution and trends observed over the last 18 years in the prevalence of undernutrition, anemia, overweight and obesity, including the most relevant findings of the ENSANUT 2006.

\section{Undernutrition}

Most of the results on magnitudes and trends of undernutrition are presented in detail in this issue. $.^{31} \mathrm{Ac}-$ cording to the $2006 \mathrm{WHO}$ growth norms ${ }^{32}$ for healthy children under five years of age the national prevalence of underweight, stunting and wasting in children of this age category are $3.4 \%, 15.5 \%$, and $2.0 \%$, respectively ${ }^{31}$ (Figure 1). According to González de Cossío et al., ${ }^{31}$ in Mexico growth faltering starts early in life. For example, in children 0-5 and 6-11 months of age the prevalence of stunting was already $14.0 \%$ and $12.8 \%$, respectively. Similarly, the national overall prevalence of wasting in children $<5$ years was $2.0 \%$ and the prevalence of wasting was more than twice as high as the average prevalence among infants $0-5$ months of age $(4.7 \%)$ and 6-12 months of age (4.5\%). ${ }^{31}$

A comparative analysis of the prevalence of underweight, stunting and wasting over the three surveys periods illustrates dramatic improvements over the last eighteen years (Figure 1). From 1988 to 2006 the prevalence of underweight decreased by $68.5 \%$ (10.8\% in 1988, $5.6 \%$ in $1999,3.4 \%$ in 2006). Similarly the prevalence of stunting decreased by $42 \%$ (26.9\% in 1988, $21.5 \%$ in $1999,15.5 \%$ in 2006) while the prevalence of wasting went down by $68 \%$ (6.2\% in 1988, 2.1\% in 1999, $2 \%$ in 2006). Given that the duration of the time periods 


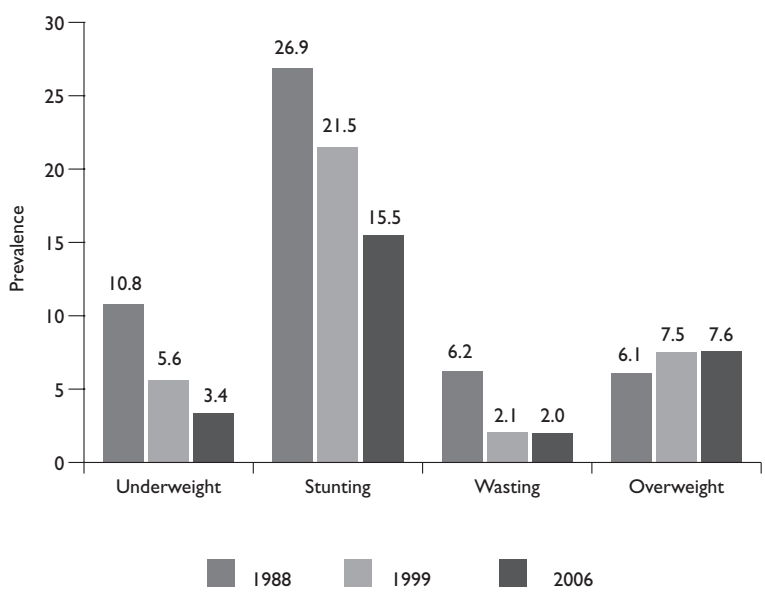

* 2006 WHO growth norms (reference 32) Source: (reference 3I)

Figure I.Prevalences* of UnderWeight, stunting, WASTING AND OVERWEIGHT IN CHILDREN < 5 Y IN 1988, 1999 AND 2006 in MeXICo

between surveys differed (11 years vs. 7 years) in order to compare the prevalences it was necessary to adjust for this difference by expressing them as average yearly percent point ( $\mathrm{pp}$ ) changes. A comparison of data from the two time periods between surveys: 1988-1999 and 1999-2006 shows that the most significant reduction in the prevalence of wasting took place during the first time period, while the shift in the prevalence of stunting was observed over both periods, but with a larger rate of decline over the second period. The decline in stunting during the 1988-1999 period was $0.49 \mathrm{pp} / \mathrm{y}$ and $0.86 \mathrm{pp} / \mathrm{y}$ during the 1999-2006. An evaluation of the relative importance of the changes over time compared to baseline prevalences (in percentage), adjusting by the duration of the period, showed that the relative decline by year was 1.8\% / y for the 1988-1999 period and 4.0\% / y during 1999-2006 period. Thus, the drop during the second period was larger both in absolute and in relative terms.

The trends and magnitude of the changes observed in the prevalence of stunting over the 18 year period is shown by region in Figure 2. Data by region, disaggregated by rural and urban areas, is presented in Figure 3. Figure 4 illustrates the prevalence of stunting according to living condition deciles.

As illustrated in figures 3 and 4, dramatic reductions in the prevalence of stunting were observed at a National level in the 18-year period, particularly for the Center (51\% reduction) and South (43\% reduction) regions. It should be noted that compared to the Mexico City and the North regions, the Center and South regions had the highest prevalence of stunting in 1988. While the prevalences in the North dropped substantially over the same time period (39\%), the prevalence in Mexico City, which was similar to prevalence in the North in 1988, remained unchanged (Figure 2). Moreover, although most of the decline in the Center and North occurred during the 1988-1999 period (76\% and 82\% of the total decline, respectively) the opposite occurred in the South region where most of the drop took place from 1999 to 2006 (90\% of the total decline).

When evaluated by rural/urban classification, the combined prevalences of stunting by region and in urban/rural areas showed the greatest reduction in the rural-center $(54 \%$ decline), rural-north $(68.1 \%$ decline) and urban-south ( $54 \%$ decline) locations over the 18 year period. As illustrated in Figure 3, the poorest area (rural-south), with the highest prevalence in 1988, experienced a lower decline $(31.6 \%)$. A comparison of the two periods between surveys reveals a larger decline during the 1988-1999 period in the rural-center and urban-south (between $72 \%$ and $75 \%$ of total drop), respective to 1999-2006. Contrastingly, an increase in the prevalence of stunting was observed in the rural-south region between 1988 and 1999, followed by a large decline during the 1999-2006 period. In absolute terms the decline in stunting in the rural south sub-region during 1999-2006 was the most significant one observed relative to all other sub-regions $(2.6 \mathrm{pp} / \mathrm{y})$.

Important changes were observed by SES level and ethnic background over time. Declines in the prevalence

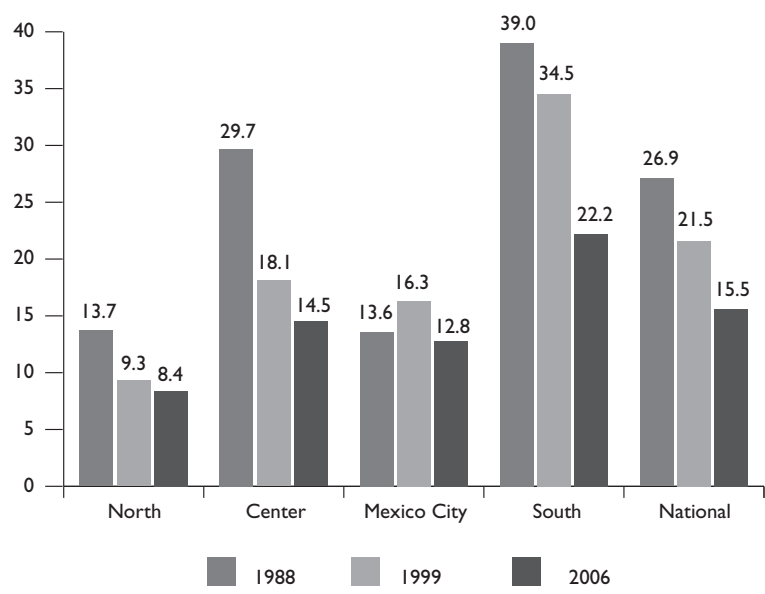

* 2006 WHO growth norms (reference 32)

Figure 2. Prevalences* of StUnting in ChildRen $<5$ Y IN 1988, 1999 AND 2006 BY REGION 


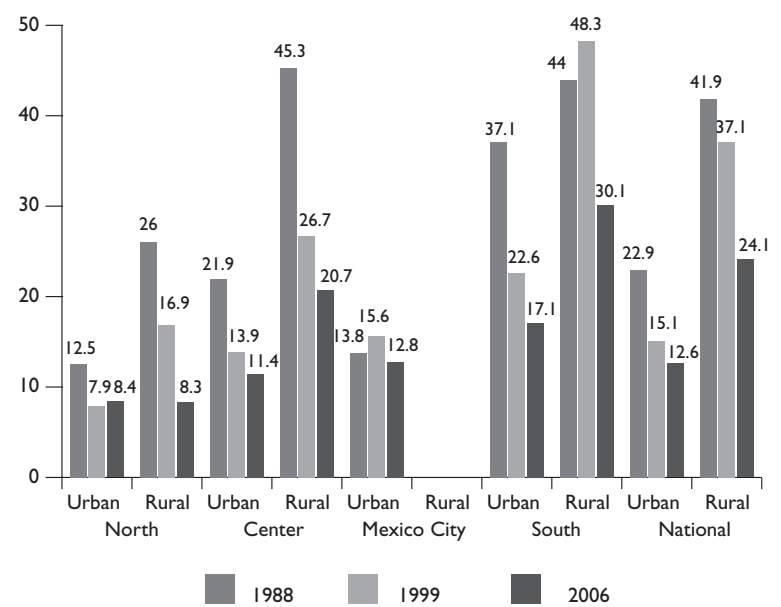

* 2006 WHO growth norms (reference 32)

Figure 3. Prevalences* of stunting in Children $<5$ Y IN 1988, 1999 AND 2006 BY REGION AND URBAN OR RURAL AREAS

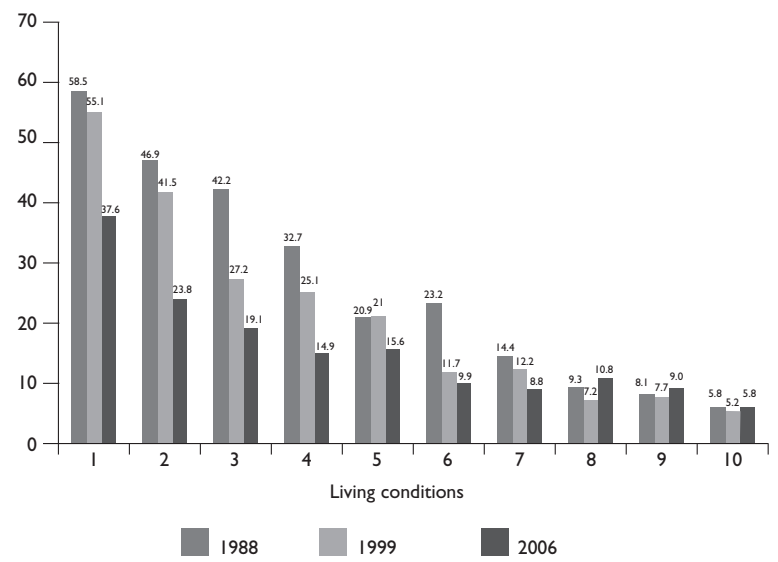

* 2006 WHO growth norms (reference 32)

Figure 4. Prevalences* of Stunting in Children $<5$ y in 1988, 1999 AND 2006 BY DECILES OF LIVING CONDITIONS

of stunting, ranging from $36 \%$ to $55 \%$, were noted in the four lower deciles of the living conditions distribution index between 1988 and 2006. Contrastingly, only modest or no changes were observed among most upper deciles (Figure 4). The most important changes in the prevalence of stunting in the lower deciles $(90 \%$ and $77 \%$ of total decline) took place between 1999 and 2006.

When evaluated according to ethnic background, the prevalence of stunting in children over the 18 year period shows larger absolute declines among Indigenous children (20.9 pp) relative to non Indigenous children (11.4 pp). However, the relative decline in the prevalence of stunting among Indigenous (38\%) is lower than that among non-Indigenous children (46\%). The decline in the prevalence of stunting among Indigenous children was almost four times more pronounced between 1999 and 2006, both in absolute (2.16 pp/year) and relative (4.4\% per year) terms, if compared to the period between 1988 and 1999 (0.53 pp/year or 0.95\% per year). It should be noted that between 1999 and 2006 the decline in the prevalence of stunting in Indigenous children was higher in both absolute $(2.16 \mathrm{pp} /$ year $v \mathrm{~s}$. $0.68 \mathrm{pp} /$ year) and relative terms (4.4\% per year $v s .3 .8 \%$ per year). In contrast, over the first 11 years of the study period considered the decline in stunting was lower among Indigenous children in both absolute $(0.53 \mathrm{pp} /$ year vs. $0.60 \mathrm{pp} /$ year $)$ and relative terms $(0.95 \%$ per year vs. $2.4 \%$ per year). However, despite the important changes observed in the prevalence of stunting among Indigenous children over the last 7 years of the study period, the prevalence of this condition remained about 2.5 times higher in Indigenous (34.1\%) than non-Indigenous (13.2\%) children in 2006 (Figure 5).

\section{Overweight and obesity}

In 2006 the combined prevalences of overweight and obesity for all age groups were strikingly high. The prevalences were $69.6 \%$ (28) and $24.3 \%$ for adults $(\geq 20$ years) and children and adolescents (2-18 years), ${ }^{24}$ respectively. Among age sub-groups prevalences of $16.7 \%$ in 2-4 year old children, $26.1 \%$ in school-age children, and $30.1 \%$ in adolescents were documented. Results for all age groups for which cross-sectional representative data was available are illustrated in Figure 6 and for children $<5 \mathrm{y}$ in Figure 1.

Preschool children (0-5 years of age using the 2006 WHO growth norms): Prevalences of overweight in children $<5$ $\mathrm{y}$, defined as weight for length / height above $+2 \mathrm{Z}$-scores of the 2006 WHO growth norms ${ }^{32}$ in 1988, 1999 and 2006 are shown in Figure 1. An increase in prevalences is shown from 1988 to 1999 and a stable prevalence from 1999 to 2006.

Preschool children (2 to 4 years of age using the IOTF system): An overall increase in the prevalence of unhealthy weight was observed between 1988 and 1999 (15.7\% to $19.7 \%$ ) followed by a slight decrease from 1999 to 2006 from $19.7 \%$ to 16.7). However, when disaggregated by subgroups and study periods the data reveal distinct trends. For example, while increases in the prevalence of 
excess weight over the 18 year period were observed in urban areas and the mid- to high- socioeconomic tertiles, a decrease was observed in the low socioeconomic tertile and in rural areas. These results point to a simultaneous increase in prevalence of unhealthy weight among wealthier populations and a decrease among the poorer populations between the first and third surveys.

School Age Children (5-11 years of age): Excess BMI among children ages 5-11 is widely prevalent and increasing. Given that no information for this age group was available from the 1988 survey, only data from 1999 to 2006 was considered. The combined prevalence of overweight and obesity in this age group was estimated at $18.4 \%$ in 1999 and $26.2 \%$ in $2006 .{ }^{24}$ An increase of 7.8 percentage points or $42.4 \%$, relative to the baseline prevalence, was observed over the 7-year period. Dramatic increases in the prevalence of overweight and obesity were observed in every region and for all socioeconomic subgroups. The rate of obesity was particularly high among children in the low socioeconomic tertile (1.6\% to $4.9 \%)$ and among children in the south region (3.7\% to $7.4 \%)$. Overall, the combined prevalence of overweight and obesity in 2006 was higher among school age children in Mexico City (33.3\%), followed by children in the North $(29.2 \%)$, Central $(26.6 \%)$ and South regions $(22.5 \%)$.

Adolescents (12 to 18 years of age): Data on adolescent females was available and analyzed from all three surveys, while data on adolescent males was only available for 2006. An estimated 30.8\% of adolescent females and $29.3 \%$ of adolescent males were overweight or obese in 2006. The positive trend in the prevalence of excess weight from 1988 to 2006 was striking. The combined prevalence of overweight and obesity rose from $8.9 \%$ in 1988 to $24.9 \%$ in 1999 and $30.8 \%$ in 2006. These increments represent close to a 3 -fold increase in prevalences from 1988 to 1999 and almost a 4-fold increase from 1988 to 2006 (Figure 6). Between 1988 and 1999 the prevalence of overweight observed almost a 3-fold increase (7.4\% to $21.0 \%$ ) while the prevalence of obesity nearly doubled (1.5\% to 3.9\%). Between 1999 and 2006 the prevalence of overweight increased slightly (21\% to $23.7 \%$ ) while obesity went from $3.9 \%$ to $8.8 \%$. Similar patterns were observed in all regions, across socioeconomic tertiles and in rural and urban areas. However the magnitude of the increases was higher in Mexico City, urban areas and the two upper socioeconomic tertiles.

Adults (20-59 years of age) and Older adults ( $\geq 60$ years of age): An estimated $69.6 \%$ of Mexican adults were classified as either overweight or obese in $2006 .{ }^{28}$ Specifically, 39.7\% of adults were overweight and 29.9\% were obese. The prevalence of obesity was significantly higher among females compared to men (women, 36.9\% vs. men, 23.5\%). In turn, the prevalence of overweight was higher among men than among women (women, 36.9\% vs. men, $43.2 \%$ ). The overall prevalence of abdominal obesity among all adults $\geq 20$ was $75.9 \%$. The combined prevalence of overweight and obesity in adults was strikingly high for all socioeconomic tertiles, regions, and age groups and in rural and urban areas, with small noticeable differences among these categories. The region with the highest combined prevalence of excess weight was the North region $(71.8 \%)$, followed by Mexico City $(71.4 \%)$, the Center $(69.9 \%)$ and the South $(66.9 \%)$. The middle and high tertiles of SES had the highest prevalences (middle $\mathrm{SES}=72.3$ high SES=71.5\%) while the Low SES had the lowest $(63.9 \%)$. In rural areas the prevalence of excess weight was lower $(64.1 \%)$ than in urban areas (70.9\%). An upward trend in the prevalence of excess weight was observed for young and middle-aged adults; a slight downward trend was observed in the oldest age group. The prevalence of overweight among adults over the age of 60 was $70.1 \% .^{28}$

BMI data was collected from women ages 20-49 in all three national surveys; excess weight trends considering all three periods have been analyzed and are shown in Figure 6. The changes observed over the 18 year time period are astounding. The combined prevalence of overweight and obesity almost doubled during the study period. Between 1988 and 1999 the prevalence of obesity among women increased at a rate of 1.4 percentage points per year or $162 \%$ in a span of 11 years (9.5\% in 1988 to almost 25\% in 1999). This upward trend was sustained from 1999 to 2006 when the prevalence increased at a rate of almost 1.1 percentage points per year or a 30\% increase in just seven years $(24.9 \%$ in 1999 to $32.4 \%$ in 2006). The prevalence of overweight increased from 1988 to 1999 but remained stable from 1999 to 2006 (Figure 6).

Figure 7 illustrates the prevalences of overweight and obesity by living conditions quintile for women ages 20-49 in 1988, 1999 and 2000. Although dramatic increases were observed among all quintiles, the most notable increases in the rate of obesity from 1988 to 2006 were observed in the lowest quintile (Q1). From 1988 to 2006 the rate of overweight and obesity grew by almost $400 \%$ in the lowest living condition quintile compared to a $55 \%$ increase in the prevalence among those in the highest quintile (Figure 7). 


\section{Anemia}

Children 1-4 years of age): From 1999 to 2006 the prevalence of anemia in children ages 1-4 declined from 28.1 to 23.7 per cent. ${ }^{30}$ The largest reductions in the prevalence of this condition were observed among younger children. In 12-23 month old infants a reduction of 13.9 percentage points ( 54.3 to $40.5 \%$ ) was observed. Among

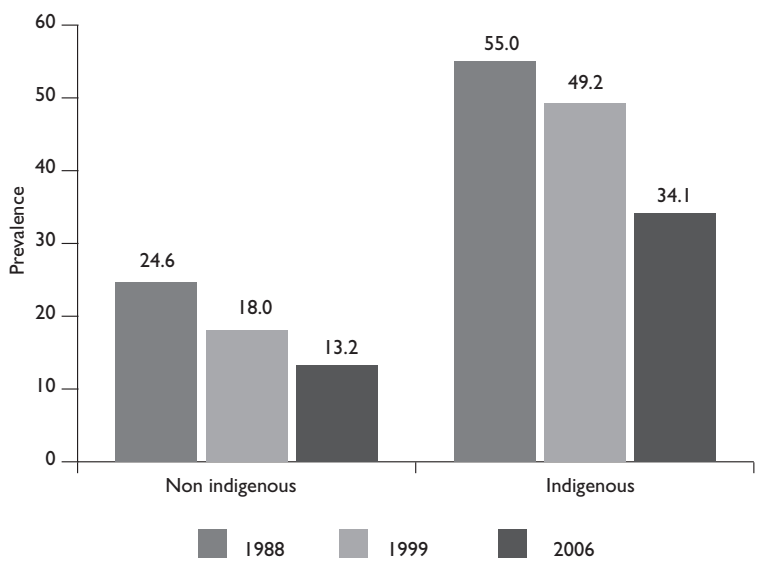

* 2006 WHO growth norms (reference 32)

Figure 5. Prevalences* of stunting in Children $<5$ Y IN 1988, 1999 AND 2006 FOR INDIGENOUS AND NON INDIGENOUS HOUSEHOLDS

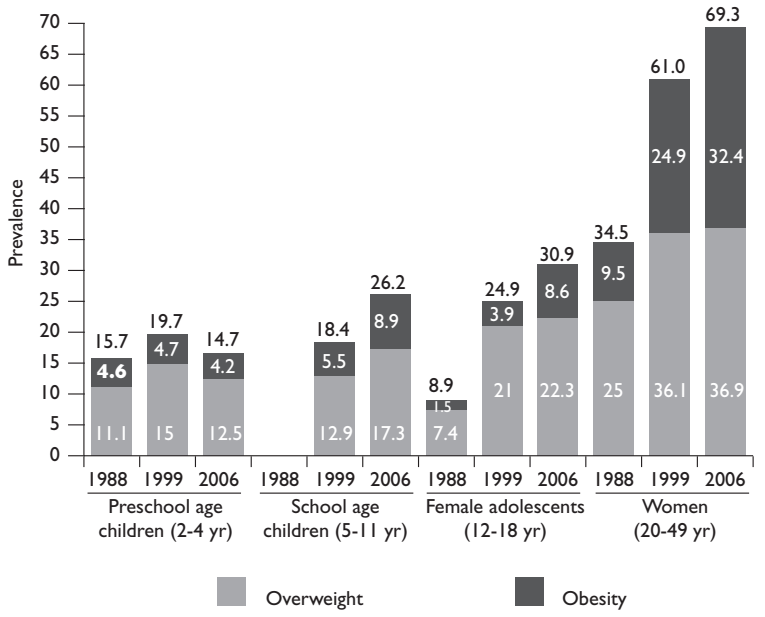

Figure 6. OVerweight and Obesity in Children (2-4 and 5-I I Y), FEMALE ADOLESCENTS ( $12-18$ Y) AND WOMEN (20-49 Y) FROM 1988 TO 2006

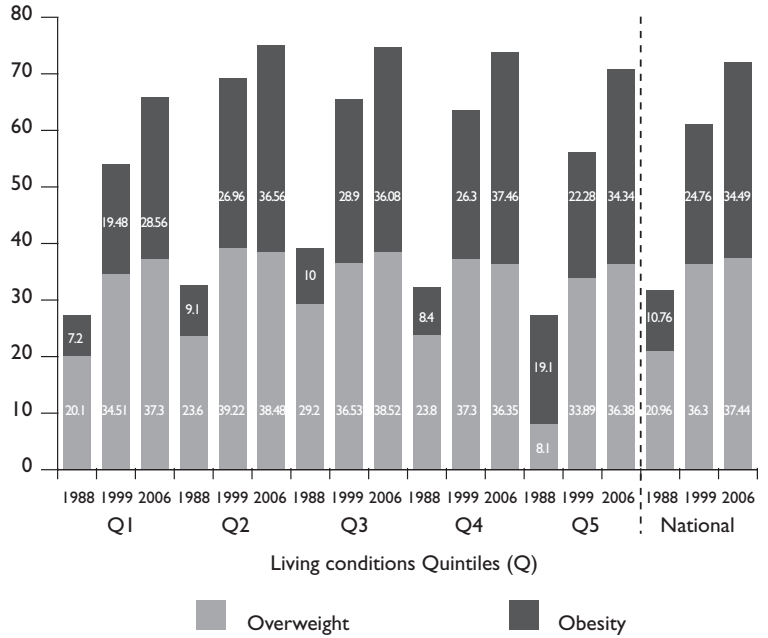

Figure 7. Prevalences of Overweight and obesity in WOMEN 20-49 YEARS BY LIVING CONDITIONS QUINTILES IN 1988, 1999 AND 2006

24-35 month old infants there was a 7.8 percentage point reduction (36.2 to $28.3 \%$ ). When analyzed by living condition tertile the most significant drops in the prevalence of anemia were observed in the middle tertile (9.3pp) followed by the lowest tertile (4.3pp) and the highest tertile (3pp). The largest absolute decline in the prevalence of anemia among 1 to $4 \mathrm{y}$ old children in all subgroups was observed among Indigenous children (12.9 pp), which went from $39.6 \%$ in 1999 to $26.7 \%$ in 2006 (Figure 8). At the regional level, notable differences in the prevalence of anemia prevailed. In contrast to the Center, North, and Mexico City regions, which averaged an improvement of 6.4 percentage points in the rate of anemia, the South region had the lowest improvement in this age group with a 3.1 percentage point prevalence decline (31.1\% in 1999 to $28.0 \%$ in 2006).

School Age children (5-11 years of age): Between 1999 and 2006 the general prevalence of anemia decreased for children ages 5 to 8 and 9 to 11 years of age from 29.7 to $20.8 \%$ and from 19.4 to $14.7 \%$, respectively. ${ }^{30}$ No significant differences were observed in the prevalence of anemia after disaggregating by sex, urban/rural location, or ethnicity. However, at a regional level, an increase of 24.3\% (3.4pp) was observed among children living in Mexico City (from $14.0 \%$ in 1999 to $17.4 \%$ in 2006).

Adult Women (12-49 years of age): In 2006, the national prevalence of anemia among women of reproductive 


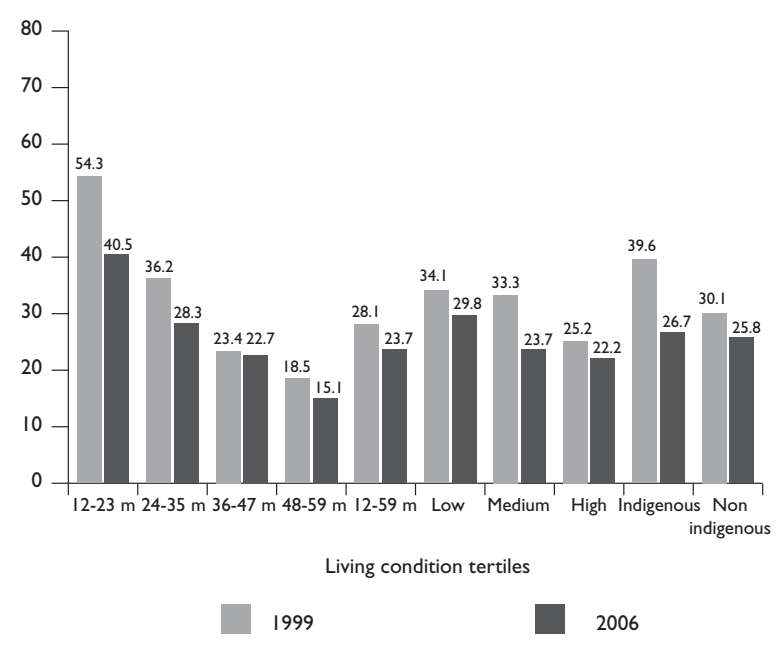

*2006 WHO growth norms (reference 32 )

Figure 8. Prevalence* of anemia in Children I-4 Y in 1999 AND 2006 BY AGE

age (12-49 years) was $20.2 \%$ among pregnant women and $15.5 \%$ in non-pregnant women. ${ }^{29}$ The corresponding prevalences in 1999 were $27.8 \%$ and $20.8 \%$, respectively. In a 7-year span, this decrease signified about a quarter percentage change (27.3\% and $25.5 \%$ respectively among pregnant and non-pregnant women). In both surveys, higher rates of anemia where observed as age increased. The reduction in the prevalence of anemia was larger among non- pregnant Indigenous women (24.8 to $17.6 \%$ or a $29 \%$ reduction) compared to the non-Indigenous (20.4 to $16.2 \%$ or a $20.9 \%$ reduction). Hence, the existing gap in the prevalence of anemia between Indigenous and non Indigenous women decreased considerably since 1999. Contrary to the 1999 survey, in 2006 there was a positive association between increasing BMI and anemia. Low SES, living in the north and south regions, and having more than 3 children, were also factors associated to a higher prevalence of anemia in women.

Older adults (adults over 50 years of age). As part of the 2006 survey data on anemia were collected for the first time among adults 50 years of age and over. The national prevalence of anemia in this age group was $23.7 \%$. The highest prevalence was observed in urban areas where $32.1 \%$ of women and $24.1 \%$ of males were anemic. Adults over the age of 80 had the highest prevalence compared to adults ages 50 to 79 . The highest prevalence of anemia in women over 50 was observed in the Northern region (34.7\%). Contrastingly, the highest prevalence of anemia in males was observed in the South region $(16.8 \%) .{ }^{45}$

\section{Discussion and Conclusion}

Over the last two decades Mexico has made important strides in successfully addressing pressing nutrition challenges; many challenges to be overcome still remain. Since 1988 the prevalence of conditions like undernutrition and anemia have been reduced and, while these conditions continue to be reason of concern for specific subpopulations, the magnitude of the overall progress made to date cannot be disregarded. On the other hand, despite the documented reductions, the prevalence of stunting remains high, particularly among lower income and indigenous infants and children. Similarly, high prevalences of anemia are still widespread in children, women of reproductive age and the elderly. Yet, it is the dramatic rise in the prevalence of unhealthy weight (overweight and obesity) over the last 18 years that currently poses the most daunting public health challenge facing the Mexican population.

A remarkable decline in the prevalence of wasting and stunting occurred between 1988 and 2006. While the most notable decline in the prevalence of wasting took place in the time period between the 1988 and 1999 surveys, the decline in the prevalence of stunting was most notable in the period from 1999 to 2006 . The drop in the overall prevalence of stunting is of particular relevance and merits further discussion. For the most part, the reductions in the prevalence of stunting took place among lower socioeconomic households, in the rural area, in the south and among Indigenous population. As a result, the gaps between socioeconomic groups, rural and urban areas, geographic regions and Indigenous or non-Indigenous population were substantially reduced, although considerable disparities persist. A noteworthy upturn was also observed with regards to the prevalence of anemia in children $<5$ years of age. The most notable decline took place among children 12-23 months of age. A reduction in the prevalence of anemia in this particular age group is important because of the critical window of cognitive and motor development during the first two years of life. A notable decline in the prevalence of anemia among pregnant and lactating women was also observed between 1999 and 2006. The decline was particularly important in non-Indigenous non-pregnant women. However, despite the improvements observed to date, the prevalence of anemia remains high in children $<5$ years of age and among pregnant and lactating women, and should continue to be regarded as a public health priority. The high prevalence of anemia among 
older adults, documented for the first time in 2006, also merits particular attention.

The purpose of this paper is to document the magnitude, distribution and trends in the nutritional status of the Mexican population. It is beyond its scope to identify the causes leading to a condition or changes in the prevalences observed over time. However, it could be speculated that the larger declines in stunting between 1999 and 2006, most notably among the poor, were due to a new generation of nutrition programs implemented in the mid-1990s. Most notably the Oportunidades program, formerly Progresa, is one of the most progressive social programs in Mexico. Its evidence based model for targeting the poor has proven effective and earned the program international recognition. The program, targeted to low income families, children $<2$ years of age and pregnant and lactating women, also had a strong evaluation methodology built into its design as an essential component. ${ }^{46,47}$ In addition to conditional cash transfers, the program provides micronutrient fortified foods to all children 6-23 months of age, underweight children 2-4 years of age and to pregnant and lactating women. Another unique feature of the nutrition component of the program is that it was designed by a group of nutrition experts on the basis of existing evidence on the nutritional status of the population. Thus, supplements were designed specifically for the young children and women benefiting from the program and contained the nutrients most deficient in their diet. Evaluations of the nutritional impact of the program have demonstrated a positive effect on improved growth and on the reduction of anemia. 48,49

Another possible contributing factor in the decline in stunting observed between 1999 and 2006 is the success of national poverty reduction efforts and related improvements in living conditions during the same period ${ }^{50}$ However, it is unlikely that a reduction in poverty levels and improvements in living conditions alone can fully explain the changes, particularly because the most notable changes were observed precisely among the poorest population. It is more likely that the combination of improved living conditions and reductions in the levels of poverty, along with an adequate design, targeting, and implementation of Oportunidades, had an impact in the patterns of decline of stunting observed during the period.

A novel contribution of this paper is the use of the 2006 World Health Organization (WHO) growth curves $^{32}$ for the first time to assess the growth of infants and young children from 1988 to 2006 in Mexico. These new guidelines describe the expected growth pattern of children ages 0 to 5 when fed according to WHO recommendations, which identifies breastfed infant as the normative model for growth and development. The results obtained using the new set of standards call for a reconsideration of child malnutrition in Mexico. ${ }^{31}$ If the previous references had been used to analyze 2006 data, the rate of stunting would have been underestimated by 2.9 percentage points and the rate of wasting by 0.4 percentage points. Most notably, the prevalence of wasting in the first 6 months of life, as estimated with the old WHO growth references, had a twenty-fold underestimation rate. These findings suggest that the prevalence of wasting and stunting for this age group had been underestimated in the past. ${ }^{31,51}$ Hence, the use of a new set of norms highlights the existence of nutrition problems among those in the earliest stages of life. Moreover, the results yield using the new set of standards highlight the importance of effective nutrition interventions targeting pregnancy in order to promote appropriate intrauterine nutrition, as well as the need to improve breastfeeding practices during the first six months of life, as recommended by the WHO. Additionally, the widespread inadequate breastfeeding and infant feeding practices in Mexico has also been documented. For example, the introduction of a variety of beverages, infant formula and whole milk, and solid foods, usually takes place prior to the recommended period of introduction of foods different from breast milk. ${ }^{19}$ Given the implications of the low levels of exclusive breastfeeding observed, the promotion of infant feeding practices in accordance with the WHO recommendations should become a public health priority in Mexico.

Comparable data collected since 1988 shows a steady increase in the prevalence of excess weight in Mexico. This increase has been documented among all age groups irrespective of sex, socioeconomic status or geographic location (Figure 6). The rise in excess weight was also common to all living conditions quintiles; moreover the prevalence of obesity increased more in the lower SES quintile, disproving the notion that the problem is one exclusive among those better off. The only age group in which excess weight prevalences have not increased steadily is the group of children 2-4 y of age, in which a decrease was observed between 1999 and 2006, particularly among the poor. It is likely that the decrease observed in the prevalence of excess weight for this age group during the study period is the result of the decline in the prevalence of stunting described earlier. Increased growth in height (the BMI denominator) had probably an effect on a lower BMI ratio.

The dramatic increases in the prevalence of overweight and obesity call for immediate effective action. A National Strategy for the Prevention of Obesity, based on the best international practices, such as the WHO Global Strategy on Diet, Physical Activity and 
Health, developed using the best available evidence, ${ }^{52}$ is urgently needed in Mexico and should be part of the WHO Global Strategy. ${ }^{53}$

As previously noted, the identification of the causes of the rapid increase in excess weight in the Mexican population, as well as other nutrition challenges, is beyond the scope of this paper. However, several of the articles published in this issue discuss some known determinants of the disjuncture between energy intake and expenditure patterns, which may in part explain the growing obesity epidemic. It is generally agreed that energy imbalance and excess weight result from the interaction of environmental, economic and genetic factors. Judged against the 1999 survey, reported energy and nutrient intake among most groups were higher in 2006. Most notably, an important proportion of the adult population reported excessive carbohydrate and fat intakes. ${ }^{27}$ In turn, $90 \%$ of adolescents reported consuming sweetened beverages regularly. ${ }^{54}$ Analogous to the consumptions of low nutritional value foods, findings from the 2006 survey point to a limited consumption of fruits and vegetables and increase in the consumption of sweetened beverages. Overall, less than optimal consumption of fruits and vegetables was common to all age groups. ${ }^{55} \mathrm{Also}$, among adolescents the emergence of abnormal eating behaviors, including binge and restrictive eating and purging, was documented. ${ }^{56}$

It should also be noted that recently the issue of beverage consumption among the Mexican population has received increased attention. In 2008 as part of a study led by a group of nutrition experts to evaluate beverage consumption patterns concluded that caloric beverages provide more than $20 \%$ of the total energy intake of Mexican adolescents and adults. Based on these findings, an expert panel appointed by the Secretary of Health established consumption recommendations by beverage category, which can be included in interventions to prevent obesity. ${ }^{57}$ Other factors associated with the increase in overweight and obesity, as argued by articles in this issue, include an apparent increase in the consumption of energy dense foods coupled by a limited consumption of fiber as well as declining levels of physical activity among the general population. Screen time, or time spent engaging in passive activities such as watching television, playing video games, or using a computer, was positively associated with overweight and obesity among Mexican adolescents. ${ }^{58}$ Similarly, a strong inverse relationship between physical activity levels and obesity was found among adult males. ${ }^{59}$

In sum, the data collected as part of the ENSANUT 2006 and presented in this issue provides a snapshot of the health and nutrition status of the Mexican population at the onset of a new millennium. Thus, it provides an opportunity to cogitate on the implications of the changes and patterns observed since the first survey conducted in 1988. Twenty years ago the ENN 88 revealed high prevalences of wasting, stunting and micronutrient deficiencies common to an inadequate diet among large numbers of women and children. Important differences between rural and urban populations, most notably with regards to the impact of inequity on nutritional status, were also documented. Based on the findings of the first survey, existing programs such as Progresa (now Oportunidades) were designed and public policies were developed to respond to the observed gaps and pressing nutritional needs of the population at the end of the 1990s. Eleven years later, building upon the original survey design, the ENN 99 evaluated the progress made from the last survey while also expanding in its scope and sampling methodology. The 1999 survey was conducted almost immediately after the initiation of Progresa. In a way, it was also envisioned as a baseline to assess changes associated with the program. Results showed a dramatic reduction in the prevalence of wasting, but less than desirable advances in the reduction of stunting and of anemia among infants and pregnant women. For the first time, the findings of this survey pointed to the emergence of overweight and obesity as a public health problem. Yet, while addressing stunting, micronutrient deficiencies and anemia became a priority in the agenda of most government health, nutrition, and social development program, limited efforts were put towards attending to the population's seemly growing waistlines.

The most recent data from the ENSANUT 2006 confirms that Mexico faces a daunting challenge. The epidemic proportion of overweight and obesity is already comparable to that observed in developed countries and among the highest in the world. Analogous to undernutrition, excess body fat can lead to a myriad of debilitating and life threatening conditions. In turn, these conditions compromise the quality of life and productivity of those who suffer from it and can seriously strain the public health care system. As a result, the short and long term implications of failing to act upon the obesity epidemic are sizable. At the outset there is a need to re-evaluate the objectives and provisions of existing national nutrition and social assistance programs historically targeted at countering nutritional deficiencies.

The successful reduction in the prevalence of nutritional challenges such as anemia and undernutrition at a national level documented by the ENN, particularly since 1999, illustrates the systems capability of developing effective strategies to halt and reverse pressing nutritional issues. Concerned efforts should be sustained in the areas of anemia and undernutrition and new strategies are required to reduce the prevalences 
among the poor and particularly among Indigenous population. Yet, the double burden of under- and overnutrition should be recognized and acting to change the tide of overweight and obesity must become a public health priority. Investing in the education of the general population on general health and nutrition problems, including the risks of excess weight and the importance of physical activity trusting their will power to pursue the actions recommended, is not nearly enough. The development of large-scale programs and public policies to support these programs is imperative. In all, there is a need to promote environmental changes that help Mexicans eat better and be more active. More specifically, the advancement of concerned efforts to promote school wellness policies, such as increasing physical activity in schools, regulating the types of foods available during schools hours, the promotion of responsible food marketing to children and adolescents, and securing every individuals access to affordable and nutritious diets is imperative. The health and economic wellbeing of generations to come depends on it.

\section{References}

I. Sepúlveda-Amor J, Lezana-Hernandez M,Tapia-Conyer R,Valdespino J, Madrigal H, Kumate J. [Nutritional status of pre-school children and women in Mexico: results of a probabilistic national survey]. Gac Med Mex 1990; 126: 207-24.

2. Rivera J, Long K, González-Cossío T, Parra S, Rivera M, Rosado JL. Nutrición y Salud: Un menú para la familia. En: Cuadernos de Salud. Problemas Pre-transicionales. México: Secretaría de Salud, 1994. 3. Rivera J, González-Cossío T, Flores M, Hernández M, Lezana MA, Sepúlveda J. Déficit de talla y emaciación en menores de cinco años en distintas regiones y estratos en México. Salud Publica Mex 1995; 37:95-107. 4. Martínez H, González-Cossío T, Flores M, Rivera J, Lezana MA, Sepúlveda J.Anemia en Mujeres en edad reproductiva, resultados de una encuesta probabilística nacional. Salud Publica Mex 1995; 37:108-II9.

5. Hernández B, Peterson K, Sobol A, Rivera J, Sepúlveda J, Lezana MA. Sobrepeso en mujeres de 12 a 49 años y niños menores de cinco años en México. Salud Publica Mex 1996; 38:178-188.

6. Flores M, Melgar H, Cortés C, Rivera M, Rivera J, Sepúlveda J. Consumo de energía y nutrimentos en mujeres mexicanas en edad reproductiva. Salud Publica Mex 1998; 40:161-171.

7. Rivera J, Cortés C, Flores M, González-Cossío T. Capacidad de peso para edad y longitud para edad para predecir desmedro a los tres años de vida. Salud Publica Mex 1998; 40:127-132.

8. Rivera J, Monterrubio E, González-Cossío T, García-Feregrino R, García-Guerra A, Sepúlveda-Amor J. Nutritional status of indigenous children younger than five years of age in Mexico: Results of a National Probabilistic Survey. Salud Publica Mex 2003;45(4):466-476.

9. González-Cossío T, Moreno-Macías H, Rivera J,Villalpando S, ShamahLevy T, Monterrubio E, Hernández-Garduño A. Beast-feeding practices in Mexico: Results from the Second National Nutrition Survey 1999. Salud Publica Mex 2003;45(4):477-489.

I0.Villalpando S, Shamah T, Ramirez Cl, Mejía-Rodríguez F, Rivera

J. Prevalence of anemia in children I-12 years of age. Results from a Nationwide Probabilistic Survey in Mexico, Salud Publica Mex 2003;45(4):490-498.

I I. Shamah Levy T,Villalpando S, Rivera J, Mejía-Rodríguez F, CamachoCisneros M, Monterrubio E. Anemia in Mexican women:A public health problem. Salud Publica Mex 2003;45(4):499-507.

12.Villalpando S, Montalvo-Velarde I, Zambrano Chem N, García-Guerra A, Ramírez Silva $\mathrm{Cl}$, Shamah T, Rivera J.Vitamins A, and $\mathrm{C}$ and folate status in Mexican children under 12 years and women I2-49 years:A probabilistic national survey. Salud Publica Mex 2003;45(4):508-5I9. 13.Villalpando S, García-Guerra A, Ramírez Silva Cl, Mejía-Rodríguez F, Matute-Chem G, Shamah-Levy T, Rivera J. Iron, zinc and iodine status in Mexican children under 12 years and women $12-49$ years of age. A probabilistic national survey. Salud Publica Mex 2003;45(4):520-529. 14. Barquera S, Rivera J, Espinosa-Montero J, Safdie M, Campirano F, Monterrubio E. Energy and nutrient consumption in Mexican women 12 49 years of age. Analysis of the National Survey 1999. Salud Publica Mex 2003;45(4):530-539.

I5. Barquera S, Rivera J, Safdie M, Flores M, Campos-Nonato I., Campirano F. Energy and nutrient intake in preschool and school age Mexican Children: National Nutrition survey 1999. Salud Publica Mex 2003;45(4):540-550.

16. Hernández B, Cuevas-Nasu L, Shamah-Levy T, Monterrubio E, RamírezSilva Cl, García Feregrino R, Rivera J, Sepúlveda-Amor J. Factors associated with overweight and obesity in Mexican school-age children: results from the National Nutrition Survey 1999. Salud Publica Mex 2003;45(4):55I-557. 17. Resano-Pérez E. Méndez-Ramírez I, Shamah Levy T, Rivera JA, Sepúlveda Amor J. Methods of the National Nutrition Survey 1999. Salud Publica Mex 2003;45(4):558-564.

18. Rivera J, Sepúlveda-Amor J. Conclusions from the Mexican National Nutrition Survey 1999:Translating results into nutrition policy. Salud Publica Mex 2003;45(4):565-575.

19. González-Cossío T, Rivera-Dommarco J, Moreno-Macías H, Monterrubio E, Sepúlveda J. Poor compliance with appropriate feeding practices in children under $2 y$ in Mexico. J Nutr 2006; 136: 2928-2933 20. Resano-Perez E, Mendez-Ramirez I, Shamah-Levy T, Rivera JA, Sepúlveda-Amor J. Methods of the National Nutrition Survey 1999. Salud Publica Mex 2003; 45 (suppl 4): S558-64

21. Rivera Dommarco J, Shamah Levy T,Villalpando Hernández S, González de Cossio T, Hernández Prado B, Sepúlveda J. Encuesta Nacional de Nutrición 1999. Estado Nutricio en Niños y Mujeres en México. Cuernavaca, Morelos, México: Instituto Nacional de Salud Pública, 200 I. 22. Olaiz-Fernández G, Rivera-Dommarco J, Shamah-Levy T, Rojas R, Villalpando-Hernández S, Hernández-Ávila M, et al. Encuesta Nacional de Salud y Nutrición 2006. Cuernavaca, México: Instituto Nacional de Salud Pública, 2006.

23. Rodriguez Ramirez S, Mundo Rosas V, Jimenez Aguilar A, Shamah Levy T. Methodology for the analysis of dietary data from the National Health and Nutrition Survey 2006. Salud Publica Mex 2009;5I.

24. Bonvecchio A, Safdie M, Monterrubio E, Gust T,Villalpando S, Rivera J. Overweight and obesity trends in Mexican children 2 to 18 years of age from 1988 to 2006: Results of the National Health and Nutrition Survey 2006. Salud Publica Mex 2009;51.

25. Barquera S, Campos-Nonato I, Hernandez-Barrera L, Flores M, Durazo-Arvizu R, Rivera J. Obesity and central adiposity in Mexican adults: results from the Mexican Health and Nutrition Survey 2006. Salud Publica Mex 2009;51.

26. Flores, M, Macias N, Rivera M, Barquera S, Hernandez L, Garcia-Guerra $A$, et al. Energy and nutrient intake among Mexican school aged children. Mexican National Health and Nutrition Survey 2006. Salud Publica Mex 2009;5I suppl 4:S540-S550.

27. Rodriguez-Ramirez S, Mundo-Rosas V, Shamah-Levy T, Ponce-Martinez $X$, Jiménez-Aguilar A, Gonzalez-de Cossio T. Energy and nutrient intake 
in Mexican adolescents: Analysis of the Mexican National Health and Nutrition Survey 2006. Salud Publica Mex 2009;5I suppl 4:S55I-S56I. 28. Barquera S, Hernández Barrera L, Campos-Nonato I, Espinosa J, Flores M, Barriguete JA, Rivera J. Energy and nutrient consumption in adults: Analysis of the Mexican Health and Nutrition Survey, 2006. Salud Publica Mex 2009;5I suppl 4:S562-S573.

29. Shamah T,Villalpando-Hernandez S, Garcia-Guerra A, Mundo-Rosas V, Mejia-Rodriguez F, Dominguez-Islas C. Anemia in Mexican women: Results of two national probabilistic surveys. Salud Publica Mex 2009;5 I suppl 4:S5I5-S522.

30.Villalpando S, Shamah-Levy T, García-Guerra A, Mundo V, Domínguez C, Mejia-Rodríguez F. The prevalence of anemia decreased in Mexican preschool and school age children from 1999 to 2006. Salud Publica Mex 2009;5I suppl 4:S507-S5I4.

3I. Gonzalez-de Cossío T, Rivera J, Unar-Munguía M, González-Castel D, Monterrubio E, Gonzalez D. Child Malnutrition in Mexico in the last 2 decades: prevalence using the new WHO-2006 growth standards. Salud Publica Mex 2009;5I suppl 4:S494-S506.

32. World Health Organization (WHO). De Onis M, Onyango A, Borghi E, Siyam A, Pinol A. Child Growth Standards. Length/height-for-age, weightfor-age, weight-for-length, weight-for-height and body mass index-for-age Methods and development. Department of Nutrition for Health and Development, World Health Organization, 2006.

33. Cole TJ, Bellizzi MC, Flegal KM, Dietz WH. Establishing a standard definition for child overweight and obesity worldwide: International survey. BMJ 2000; 320: I240-I 243.

34.World Health Organization. Physical status: The use and interpretation of anthropometry. Geneva:World Health Organization; 1995.

35. International Nutritional Anemia Consultative Group (INACG). Guidelines for the Control of Maternal Nutritional Anemia.A report of the International Nutritional Anemia Consultative Group (INAG), Washington, DC, 1989.

36. World Health Organization The prevalence of anemia in women: a tabulation of available information. Maternal Health and Safe Motherhood Programme, Geneva, Switzerland, 1992.

37. Rush D. Nutrition and maternal mortality in developing world.Am J Clin Nutr 2000; 72 (suppl):212-40S.

38. Nestel P, Davidsson L.Anemia, iron deficiency and iron deficiency anemia. INACG. March 2002.

39. Lozoff B,Wachs TD. Fuctional correlates of nutritional and early childhood-child development and behavior. In: Nutritionals Anemias. Edited by Usha Ramakrishnan. CRC; Washington D.C.200I. pp.69-87. 40. Yip R. Significance of an abnormally low or high hemoglobin concentration during pregnancy: special consideration of iron nutrition. Am J Clin Nutr 2000; 72(suppl):272S-9S.

4I. Cohen JH, Hass JD. Hemoglobin correction factors for estimating the prevalence of iron deficiency anemia in pregnant women residing at high altitudes in Bolivia: Pan Am J Public Health 1999;6(6):392-399.

42. National Research Council. Recommended Dietary Allowances. Washington, DC: National Academy Press, 1989.

43. Dietary reference intakes:Application in dietary assessment. Washington, DC: Institute of Medicine, National Academy Press, 2000:285. 44. Hair JF,Anderson RE, Tatham RL, Back WC. Multivariate data analysis with reading. 3rd edition. New York: MacMillan Publishing 1992. 45. Shamah-Levy T,Villalpando S, Rivera-Dommarco J. Results of the National Nutrition Survey 2006. Cuernavaca, Mexico: Instituto Nacional de Salud Pública, 2007
46. González de Cossío T, Rivera Dommarco J, López Acevedo G, Rubio Soto GM. Nutrición y Pobreza: Política Pública Basada en Evidencia. México: Banco Mundial / SEDESOL, 2008.

47. Rivera J, Sepúlveda-Amor J. Conclusions from the Mexican National Nutrition Survey 1999: Translating results into nutrition policy. Salud Publica Mex 2003;45(4):565-575.

48. Rivera J A, Sotrés-Alvarez D, Habicht JP, Shamah T,Villalpando S. Impact of the Mexican Program for Education, Health and Nutrition (Progresa) on rates of growth and anemia in infants and young children.A randomized effectiveness study. JAMA 2004;291:2563-2570.

49. Leroy J, García-Guerra A, Garcia R, Dominguez C, Rivera J, Neufeld LM, The Oportunidades Program Increases the Linear Growth of Children Enrolled at Young Ages in Urban Mexico.J Nutr 2008; I38:793-798. 50. CONEVAL (2008). Informe de Evaluación de la Política de Desarrollo Social en México 2008. [consulted June, 2009]. Available at: http://www. coneval.gob.mx/contenido/home/2234.pdf

5I. De Onís M, Onyango AW, Borghi E, Garza C, Yang H. Comparison of the World Health Organization (WHO) Child Growth Standards and the National Center for Health Statistics/WHO international growth reference: implications for child health programmes. Public Health Nutrition 2006; 9:942-947.

52. World Health Assembly. Resolution WHA57. 17. Global Strategy on Diet, Physical Activity and Health. In: Fiftyseventh World Health Assembly, Geneva, 22 May 2004. Geneva,World Health Organization 53. Joint WHO/FAO Expert Consultation on Diet, Nutrition and the Prevention of Chronic Diseases (2002): Geneva, Switzerland. Diet, nutrition and the prevention of chronic diseases: report of a joint WHO/ FAO expert consultation, Geneva, 28 January-I February 2002. (WHO technical report series; 916 )

54. Jimenez-Aguilar A, Flores M, Shamah-Llevy T. Sugar sweetened beverages consumption and BMI in Mexican adolescents. Mexican National Health and Nutrition Survey 2006. Salud Publica Mex; 2009:5I suppl 4:S604-S6I2.

55. Ramírez-Silva I, Rivera Dommarco J, Ponce X, Hernández Avila M. Fruit and vegetable intake in the Mexican population: Results from the Mexican National Health and Nutrition Survey 2006. Salud Publica Mex 2009;5 I suppl 4:S574-S585.

56. Barriguete-Melendez JA, Unikel-Santoncini C,Aguilar-Salinas C, Cordoba-Villalobos JA, Shamah T, Barquera S, et al. Prevalence of abnormal eating behaviors in adolescents in Mexican (Mexican National Health and Nutrition Survey 2006) Salud Publica Mex 2009;5I suppl 4:S638-S644. 57. Rivera JA, Muñoz-Hernández O, Rosas-Peralta M,Aguilar-Salinas CA, Popkin BM,Willett WC. Consumo de bebidas para una vida saludable: recomendaciones para la población mexicana. Salud Publica Mex 2008;50:173-195.

58. Morales-Ruan MC, Hernández-Prado B, Gómez-Acosta LM, ShamahLevy T, Cuevas-Nasu L. Obesity, overweight, screen time and physical activity in Mexican adolescents. Salud Publica Mex 2009;5I suppl 4:S613-S620.

59. Gómez LM, Hernández B, Morales MC, Shamah-Levy T. Physical activity and overweight/obesity in adult Mexican population. The Mexican National Health and Nutrition Survey 2006. Salud Publica Mex 2009;5 suppl 4:S62I-S629. 